\title{
Derecho, objetividad y corrección en la teoría jurídica de Alfonso Ruiz Miguel. Comentario a Alfonso Ruiz Miguel, Cuestiones de principios: entre política y Derecho
}

(2020) Centro de Estudios Políticos y Constitucionales Madrid, 615 pp.

\author{
Rodolfo Arango \\ Jurisdicción Especial para la Paz \\ rodolfo.arango@jep.gov.co
}

Cita recomendada:

Arango, R. (2021). Derecho, objetividad y corrección en la teoría jurídica de Alfonso Ruiz Miguel. Comentario a Alfonso Ruiz Miguel, Cuestiones de principios: entre política y Derecho. Eunomía. Revista en Cultura de la Legalidad, 20, pp. 426-432.

doi: https://doi.org/10.20318/eunomia.2021.6086

Recibido / received: 01/02/2021

Me ha correspondido comentar algunos aportes de teoría jurídica contenidos en los escritos compilados del profesor Alfonso Ruiz Miguel, en buena hora publicados por el Centro de Estudios Políticos y Constitucionales en 2020. Es un placer leer y estudiar los escritos de Alfonso. En ellos se evidencia la formación analítica, el conocimiento teórico y la sensibilidad política, tres cualidades indispensables para alcanzar la excelencia en el pensamiento jurídico y hacer de este algo socialmente relevante. El campo de reflexión abarca temáticas relativas al estatus científico de la dogmática jurídica (2003), al principio de jerarquía normativa (1988), a la igualdad ante la ley y el precedente (1997) y a la verdad y corrección de la decisión judicial, a propósito de la prueba ilícita (2016). Confieso que me alegró ver cómo, por diferentes caminos, confluyen nuestros intereses teórico-jurídicos; aunque, quizás, la confluencia sólo sea aparente, dada la complejidad y dificultad del objeto de estudio. No podía ser de otra manera. Indagar sobre ciencia y derecho, verdad y corrección, sistema jurídico e igualdad, abre esclusas interdisciplinarias y nos arroja a diferentes profundidades en las aguas de la epistemología, la ontología, la deontología y la filosofía práctica. Alfonso, al igual que la escuela analítica de la que proviene, rodeado de una generación de excelentes colegas con quienes dialoga, crea vasos comunicantes entre diversas disciplinas. Así, enriquece y ahonda la comprensión de los problemas jurídicos. En esta oportunidad debo limitarme solo a algunos problemas por él 
abordados. Daré prioridad a sus reflexiones sobre ciencia y derecho y a su interés por la objetividad y la corrección de la decisión judicial.

En su artículo del 2003, Alfonso indaga sobre el carácter científico de la dogmática jurídica. Nótese que la pregunta que lo inquietó no fue si el «derecho» tiene carácter científico. El profesor Ruiz Miguel habla aquí de «dogmática jurídica», no de «derecho». Con ello ancla su exploración en un concepto positivista del derecho, el derecho "puesto» o conjunto de proposiciones normativas establecidas, no el derecho como una idea de lo jurídico. Alfonso parte así de un concepto sociológico del derecho, bajo el cual la dogmática jurídica termina siendo una técnica social, en contraste con la ciencia, que a su vez entiende como una práctica descriptiva de la realidad. Mientras que la dogmática jurídica propende interpretaciones para el mantenimiento y la transformación del sistema social, la ciencia busca explicar los hechos que acaecen y predecir los que vendrán. Con este enfoque, en su ensayo de 2003 Alfonso conserva el dualismo estricto entre hechos y valores, dualismo propio del positivismo científico y jurídico a principios del siglo XX, aunque deja sembrada una inquietud digna de mención, lo que haré más adelante. Una década después, no obstante, en su escrito de 2016, al reflexionar nuevamente sobre verdad, objetividad y corrección, esta vez en relación con la práctica judicial, Alfonso acoge un concepto aspiracional del derecho, en el sentido de Ronald Dworkin (2007, p. 15). Esta diferencia no es menor. Podría denotar un cambio en la concepción del derecho -de un positivismo hartiano a un antipositivismo dworkiano o alexiano-, conversión bajo la cual -de ser cierta- la pregunta sobre el carácter científico o técnico, ahora sí, del «derecho», debería recibir una respuesta diferente en 2016 a la de 2003, con repercusiones tanto para la legitimidad del derecho como para su práctica. Sólo sería legítimo el derecho que persigue pretensiones de "verdad» (pretensiones de «corrección», en el sentido de Habermas [2002, pp. 261 ss.]) y la práctica correcta del derecho dependería no sólo de la corrección formal (validez jurídica) y la adecuación a su fin (validez social, eficacia o Zweckmässigkeit), sino de su corrección (validez moral) (Radbuch, 1980, p. 134; Alexy, 2004, p. 87). A mi juicio, y esta es la tesis central del comentario que les presento, el giro interpretativo que saluda Alfonso en su escrito de 2016 debería suponer el abandono de la dicotomía estricta entre hechos y valores, descripción y prescripción (en el sentido de Hilary Putnam [2002, pp. 133 ss.]), lo que a su vez permitiría reabrir el debate sobre el estatuto científico del derecho, con importantes repercusiones para su práctica: entre ellas, que los participantes en la actividad jurídica no deben simplemente aplicar técnicamente los dogmas normativos de forma adecuada, sino, además, mejorar el derecho para hacerlo el mejor derecho que puede ser (en el sentido de Dworkin [1988, p. 290]).

Volvamos un poco atrás para entender mi tesis de la posible conversión del profesor Ruiz Miguel, de un positivismo sociológico a uno «interpretativo». ¿Por qué Alfonso no titula su indagación de 2003: «El derecho: ¿ciencia o técnica?», y prefiere formular el problema a investigar bajo el interrogante: «La dogmática jurídica: ¿ciencia o técnica?»? La escogencia de la expresión «dogmática jurídica» en lugar de la de «derecho» no deja de tener implicaciones para la indagación. Digámoslo así, Alfonso no aborda una discusión de mayor calado sobre el concepto de derecho. Al cuestionar el carácter científico de la dogmática jurídica se casa con una noción del derecho, el «derecho puesto», positivizado, adoptado por una comunidad según normas preestablecidas, esto es, la dogmática jurídica en cuanto práctica interpretativa de un conjunto de proposiciones válidas que cumple la función de estabilizar las expectativas de comportamiento entre los partícipes de la práctica social, en las palabras de Niklas Luhmann.

El compromiso con un concepto positivista del derecho en 2003 hace que Alfonso anticipe el resultado de su indagación. Como diría Martin Heidegger, y luego 
desarrollaría Hans Georg Gadamer, la formulación de la pregunta abre un mundo y prefigura la respuesta. La ciencia se ocupa de los hechos naturales, sus métodos apuntan a describirlos, a explicarlos causalmente y predecir su ocurrencia. Los hechos sociales, a diferencia de los naturales, no pueden ser descritos o explicados, solo interpretados y comprendidos. Un acceso valorativamente neutral a ellos, en principio, nos está vedado, salvo que acudamos al método empirista o a la variante historicista (Ruiz Miguel, 2020, p. 212). Sobre los hechos sociales no gobierna el método de verificación empírica de la experiencia. Así, bajo este enfoque, la escisión estricta entre hechos y valores, ser y deber ser, fáctico y normativo, se mantiene incólume. La comprensión weberiana del derecho clausura la pregunta por la objetividad, la verdad y la corrección en la decisión judicial y esto, precisamente, porque (para el decisionismo) lo jurídico constituye un ámbito cultural irreductiblemente subjetivo, ajeno a los resultados propios de la ciencia, esto es, el conocimiento objetivo de la realidad.

Que estas sean las conclusiones de Alfonso en 2003, fluye de las tesis centrales de su escrito sobre el carácter de la dogmática jurídica. Dice: La avaloratividad -la prescindencia de juicios de valor- en las ciencias sociales que aseguraría su "cientificidad», enfrenta una disyuntiva: "es una postura difícil o un ideal irrealizable, pero debido». Alfonso encuentra un tercer camino en medio de esta disyuntiva weberiana. Dice textualmente: «... solo queda un tercer camino para quien, como el que suscribe, a la vez que desecha cualquier alarde de confianza en las virtudes de la comprensión, acepta no solo el valor metodológico que en términos de objetividad la avaloratividad tiende a garantizar sino también el criterio ético de que la ciencia ha de servir fundamentalmente para la ampliación y la profundización del conocimiento antes que para la crítica o la transformación de la realidad» (2020, p. 207). Bien entendido este punto de vista -afirma- sirve para relativizar la idea de la imposibilidad de la objetividad avalorativa en las ciencias sociales. Es una cuestión de grado. Sólo así, continúa, «es coherente defender la deseabilidad de la exclusión de valores como exigencia para el conocimiento objetivo, pues sólo desde un concepto relativo y graduable de imposibilidad cabe creer en la capacidad de autocorrección y, por lo tanto, de perfeccionamiento por parte de las ciencias sociales» (ibíd.). No obstante, esta dificultad metodológica lleva a resultados endebles en las ciencias sociales, hasta el punto de que estas son denominadas "ciencias blandas", lo que se refleja en lo endebles de sus resultados (2020, p. 208). A su juicio, las ciencias sociales tienen resultados más pobres que las ciencias naturales no tanto por el menor desarrollo sino por la mayor complejidad de los hechos sociales (ibíd.). Lo cierto es que, dice Alfonso, «en la secuencia descripción-explicación-predicción, las ciencias sociales se encuentran menos elaboradas y, en todo caso, son mucho menos satisfactorias y ricas que las naturales» (2020, p. 209). Así, el derecho, visto como fenómeno social, puede ofrecerse como objeto de estudio científico de carácter empírico, como lo muestra la sociología del derecho, la criminología o la sociología política. Pero, para Alfonso, es dudoso que la ciencia del derecho o dogmática jurídica, dado su objeto eminentemente social o cultural, pueda considerarse científica. En este punto sostiene que «la discusión sobre su cientificidad se ha de decidir en relación con sus métodos, sus resultados y, en fin, sus funciones» (2020, p. 211). En cuanto a los métodos, «la pretensión hermenéutica de otorgar objetividad a las valoraciones jurídicas -sostiene Alfonso- es, me parece, producto de una ilusión» (2020, p. 214). Para él, que la comprensión de las normas jurídicas consista en describir sus valoraciones, es una ilusión; más plausible resulta afirmar que los métodos de la dogmática jurídica componen un tipo de actividad de reelaboración que atribuye valoraciones al conjunto normativo interpretado (ibíd.). En cuanto a sus resultados, la dogmática jurídica se aleja de las ciencias naturales e incluso de otras ciencias sociales, como la economía, la sociología o la historia, en tanto se analicen bajo los cánones metodológicos empiristas o historicistas: mientras las ciencias 
naturales predicen, explican o describen la realidad, la ciencia jurídica no es predictiva; no obtiene resultados explicativos respecto del objeto de estudio; ni ofrece descripciones o representaciones conceptuales fidedignas de la realidad (2020, pp. 216-218). En la tarea dogmático-jurídica prima la interpretación prescriptiva (2020, p. 219). En ella no se descubren, determinan, observan o analizan hechos, sino se reelaboran dogmas normativos en forma de dogmas doctrinales (ibíd.). En cuanto a las funciones, la ciencia jurídica no se fija como meta el conocimiento por el conocimiento del material dogmático, sino tres funciones prácticas fundamentales: la didáctica, la integradora y la político-jurídica (2020, p. 220). Al final del análisis, la dogmática jurídica no pasa el test de cientificidad. Dice Alfonso: «Todo sumado, no parece que haya justificación mayor para concluir que la llamada ciencia jurídica sea propiamente una ciencia. Más bien, la secular insistencia de muchos juristas en tildarla de tal ha tendido a ocultar su carácter de técnica social y, con ello, sus inevitables implicaciones ideológicas» (2020, p. 223).

A propósito de la discusión sobre la exclusión de la prueba ilícita como regla del derecho procesal, en 2016 Alfonso -no sin dificultad ya que considera «no tan insensata» su posición de defender la tesis de la única respuesta correcta en el derecho (2020, p. 293)-, confiesa haber llegado a una conclusión «con cierta reluctancia», debido su desconfianza general hacia la ponderación (2020, p. 297). Desde un punto de vista interno a la práctica jurídica, el profesor Ruiz Miguel le da cabida a la búsqueda de verdad y de respuestas correctas en la argumentación normativa (2020, pp. 295-296, n. 31). Aparentemente categorías antes reservadas a la ciencia -como las de la verdad, la objetividad y la corrección-, son admitidas en el ámbito del razonamiento jurídico; tal admisión llega hasta el punto de que un jurista que no pretenda hacer de la práctica del derecho en la que vive el mejor derecho que puede ser (en el sentido de Dworkin), infringiría sus deberes para con la comunidad jurídica y arribaría a respuesta erróneas o falsas, ya no exclusivas de las ciencias naturales o de las ciencias sociales con raigambre empirista o historicista.

El amigo aquí homenajeado se inscribe así en un «positivismo interpretativo», el cual rectifica el normativismo de Kelsen y Hart, entre otras al dar mayor atención a la argumentación jurídica y judicial y acoger una concepción «objetivista» de la argumentación normativa, tanto jurídica como moral (2020, p. 281). La discusión sobre la exclusión de la prueba ilícita sirve para introducir un tipo de «verdad» diferente a la verdad fáctica, esto es, de correspondencia de los argumentos con la realidad. Se trata de una «verdad» relativa a la justificación normativa, a la corrección o justicia de las premisas normativas, como referente ideal que solo se puede validar en términos de coherencia (2020, p. 282). Las implicaciones del giro argumentativo en el derecho son amplias. La pretensión de verdad no se reserva a las ciencias que buscan acceder al conocimiento de los hechos, sino que abarca la justificación de premisas normativas en la ciencia jurídica. El jurista, a semejanza del historiador, busca que sus textos se acerquen a la verdad, la cual debe estar en alguna parte (2020, p. 283). «(E)xiste una pretensión de verdad en las afirmaciones de uno y otro y de que esa pretensión es compatible con la falibilidad de tales afirmaciones por distintas razones, como información deficiente o insuficiente, errores en la interpretación, etc.» (ibíd.). No obstante, a diferencia del historiador, en la búsqueda de la verdad el jurista no es totalmente libre; está sujeto a limitaciones de distinto orden, no solo prácticas como la limitación de tiempo sino normativas, como, por ejemplo, las reglas «contraepistemológicas» -en el decir de Marina Gascón- que, entre otras, imponen límites a la búsqueda de la verdad para, entre otros fines, proteger el secreto profesional y de Estado o los derechos fundamentales. Alfonso aprovecha la discusión teórica sobre el alcance de la regla de exclusión de las pruebas ilícitas para reflexionar sobre la pretensión de verdad en la aplicación del derecho. Dice: «La institución de la inadmisibilidad de las pruebas ilícitas (...) supone 
una severa excepción al criterio de la búsqueda de la verdad (...)» (2020, p. 284). Se pregunta: «cuál es la frontera ante la que debe ceder la búsqueda de la verdad, o, dicho de otro modo, cuál es la regulación que propone el mejor equilibrio entre dos grupos de valores últimos que aquí se encuentran en tensión: la determinación de la verdad como presupuesto y fin de una decisión judicial materialmente justa, por un lado, y la defensa de la legalidad y de los derechos fundamentales como presupuesto y función de una decisión judicial procedimentalmente justa, por el otro» (ibíd.). La relevancia filosófico-jurídica de la regla de exclusión la ilustra Alfonso con las posiciones opuestas entre Benjamín Cardozo y Oliver Wendell Holmes en el Tribunal Supremo de EEUU. Para Cardozo, «la prueba ilícita puede servir en el proceso si es conducente a la verdad, a la vez que los sus autores deben ser perseguidos legalmente, porque el delincuente no debe salir libre "porque la policía ha metido la pata"» (2020, p. 286). En cambio, para Holmes, «la utilización en el proceso de toda información o material derivado, incluso indirectamente, de una prueba ilícitamente obtenida, sería una violación inconstitucional de la integridad judicial que haría cómplice al Estado de los autores de la ilegalidad hasta situarlo al nivel de los delincuentes» (ibíd.). Como nos recuerda Alfonso, la posición de Holmes, salvo excepciones, ha resultado victoriosa, pero por dos razones de diverso cuño y alcance: por razones de principio o deontológicas relativas a la integridad en la conducta del Estado y por razones consecuencialistas o pragmáticas relativas a la disuasión de conductas ilegales por parte de los poderes públicos (ibíd.).

La regla de exclusión de la prueba ilícita plantea varios problemas filosóficojurídicos de envergadura, como bien la anota el autor en comento. Aquí sólo referiré uno relativo al alcance que se da en la práctica por los tribunales de diversas tradiciones jurídicas a dicha regla. No es lo mismo que se ordene la exclusión general de pruebas ilícitas (como en Italia) a que dicha exclusión se acote a pruebas que violen los derechos fundamentales (como en España) (2020, p. 287). Con acierto afirma Alfonso que «un rigorismo extremo que excluyera cualquier prueba obtenida en infracción de alguna ley o reglamento parece que carecería de fundamento suficiente para desconocer la finalidad de la búsqueda de la verdad y de persecución del delito...» (ibíd.). Como ejemplo, menciona la exclusión de la grabación por una cámara en un lugar público de un delito de agresiones porque la autoridad está en trámite de renovación de la autorización anual exigida por la ley de protección de datos (2020, pp. 287-288). Otro problema mencionado por Alfonso y que atañe al alcance de la regla de exclusión y a la justificación se refiere a si se deben excluir solo las pruebas ilícitas directas 0 , además, todas las pruebas indirectas que se derivan de las primeras, como enseña la doctrina estadounidense del «árbol envenenado». Mientras en Estados Unidos y España se impone un criterio extensivo, en Alemania e Italia la jurisprudencia ha admitido como válidas las pruebas indirectas, seguramente por no dar especial importancia al efecto disuasorio, recuerda el profesor Ruiz Miguel (2020, p. 288). Conocido es el caso, validado luego por el Tribunal Europeo de Derechos Humanos, en el que se admitieron pruebas indirectas como el ADN del secuestrador encontrado en el cadáver del niño secuestrado o la segunda confesión del asesino, quien había sido coaccionado bajo amenaza de tortura por la policía alemana a revelar el paradero del niño bajo la creencia de que aún estaba vivo (2020, p. 289). Esta complejidad en la aplicación de la regla de exclusión ha llevado al establecimiento de diversas excepciones y cualificaciones por parte de los tribunales. Es en este contexto que Alfonso introduce la importancia de admitir aquí una adecuada ponderación. Dice, en abierta crítica a la creación ad hoc de excepciones a la regla de exclusión por los tribunales, que se inclina más bien «por defender un test más transparente que, salvada siempre como límite absoluto la exclusión de la tortura, proponga ponderar la gravedad de la violación del derecho de 
la que se derivan las pruebas con la gravedad del delito en cuestión...» (2020, p. 292) ${ }^{1}$.

El profesor Ruiz Miguel adhiere explícitamente a la búsqueda de verdad, objetividad y corrección en el derecho al final de su escrito de 2016, cuando defiende la ponderación entre principios para justificar excepciones a la regla de exclusión de la prueba ilícita en contra de la alternativa que privilegia la aplicación categórica de dicha regla. Dice: "Se verá que mantengo una concepción objetivista no solo en materia de verdad fáctica sino también en materia de corrección jurídica y moral y que, además, acepto la debatida tesis de la única respuesta correcta a la mayoría de los problemas jurídicos» (2020, p. 293). El juez, a diferencia del legislador, no puede ni debe hacer uso de la discrecionalidad al desempeñar su función, sino que debe intentar «alcanzar la mejor argumentación posible y que su decisión ha de ser categóricamente correcta o incorrecta, de modo que la pretensión de corrección alude aquí a la corrección como criterio normativo de justicia (moral) o licitud (derecho),...» (2020, p. 294). Y, concluye Alfonso: «lgual que la verdad para el historiador, la corrección para el juez también "tiene que estar en alguna parte, no puede no estar"» (2020, p. 295).

La reluctancia a la creación de excepciones en la aplicación de las reglas, alimentada por su desconfianza hacia la ponderación (2020, p. 297), lleva a Alfonso a proponer límites sustantivos y procedimentales al uso -necesario, aunque indeseable- de la ponderación: 1) Como límite sustantivo aduce el valor de la certeza que proporciona disponer de reglas sin excepciones o con excepciones limitadas. «Solo ese especial cuidado con las reglas y con la justificación de excepciones llamadas a ser generalizadas cabe respetar la integridad del derecho» (ibíd.). 2) Desde el punto de vista procedimental, considera Alfonso, es necesario «disponer de una cultura que alimente la argumentación jurídica y judicial rigurosa» (2020, p. 298) que de un apropiado respeto a los precedentes judiciales. Esto vale, según el autor, tanto para precedentes verticales como horizontales, de forma que se combata el cambio de criterio sinuoso e implícito y la regla sea «adoptar overruling francos y expresos» (ibíd.).

Al final de su escrito de 2016, Alfonso abraza una concepción del derecho donde juristas y jueces deben hacer de este, un mejor derecho (2020, p. 298). Y ello sucede al dar ingreso en el ámbito judicial a las pretensiones de verdad, a la objetividad en la argumentación jurídica y a la búsqueda de la única respuesta correcta en cada caso, donde la adecuada ponderación corrige la estrictez del derecho positivo. En remembranza a Aristóteles y a la recuperación del saber moral (phronesis) en el razonamiento práctico, el cual no puede reducirse a un saber técnico (tekne) sino que debe abrirse a la equidad (epikeia) por ser esta la que corrige a la ley, siempre imperfecta dado el grado de su abstracción y generalidad (Gadamer, 2000).

Fascinan la claridad, la elegancia y la precisión de las tesis de Alfonso. La mejor tradición iusfilosófica española bebe de la escuela analítica del derecho. Sin duda, el enfoque de H.L.A Hart encontró tierra fértil en el antiguo continente, en especial en la península ibérica. Además, sorprende la capacidad de Alfonso de aterrizar la abstracción filosófica a problemas de la práctica jurídica, como sucede con

\footnotetext{
1 Páginas antes ha sostenido Alfonso, con sobrada razón y buen tino: «En realidad, el Estado no mantiene limpias las manos ni garantiza el juego limpio por excluir pruebas trivialmente ilícitas o cuando esa exclusión le impide proteger derechos más importantes. (...) Si la presunción de inocencia consiste en que nadie debe ser condenado sin la demostración de su culpabilidad mediante pruebas admisibles, la razón de la admisibilidad o no de las pruebas tiene que ser determinada con independencia de la propia presunción de inocencia» (2020, pp. 290-291).
} 
el debate de la regla de exclusión de la prueba ilícita. Pero la insensatez moderada que Alfonso confiesa, por abrir la puerta a la ponderación en la cultura positivista prevaleciente, deja algunas incógnitas, más cuando él mismo reconoce la influencia de Dworkin y Alexy y del «giro argumentativo» en la filosofía jurídica contemporánea. Como admirador de su trabajo de teoría jurídica, me quedan algunas preguntas que quisiera dejar planteadas para la discusión: Si la corrección propugnada en la práctica jurídica y judicial diverge en Dworkin y Alexy, ¿de qué lado se sitúa Alfonso? Esto, porque la corrección en Dworkin tiene carácter sustantivo, mientras que, en Alexy, es procedimental. No podía ser de otra forma: El primero es influenciado por el pragmatismo filosófico (Quine, Davidson, Putnam), el segundo se alimenta de la tradición kantiana (Kant, Weber, Kelsen) que, vía el neokantianismo, cimenta el positivismo científico y jurídico, central en las reflexiones de Alfonso en 2003. Así las cosas, en Dworkin se relajan las fronteras entre ser y deber ser, descripción y prescripción, lo que le permite desembocar en un coherentismo filosófico, tanto en las ciencias naturales como sociales, que rechaza las dicotomías y se aleja de la «objetividad con objetos» (Putnam, 2013, p. 87). Por el contrario, en Alexy las distinciones categoriales, y presumo que, en Alfonso igual, se mantienen en pie, con lo que el giro interpretativo no tiene la hondura ni el alcance filosófico que sí exhibe en la doctrina del derecho como integridad de Ronald Dworkin. En últimas, con las mismas palabras -verdad, objetividad, corrección- hablamos de cosas diferentes. Relajado el límite entre el ser y el deber ser, cuyas fronteras porosas debemos reconstruir sin resbalar en el relativismo de Richard Rorty, si queremos insistir en la importancia de la filosofía del derecho para la práctica judicial, parece tener poco sentido decir que la corrección, como la verdad «tiene que estar en alguna parte» esperando a ser encontrada. Por el contrario, la defensa de una «objetividad sin objetos» nos invita a desontologizar la discusión y a hallar en el constructivismo la mejor teoría disponible para fundamentar objetivamente las decisiones correctas. Sea la oportunidad para dejar planteada esta discusión, felizmente suscitada por las ricas y sofisticadas reflexiones de un maravilloso teórico del derecho.

\section{Bibliografía}

Alexy, R. (2004). El concepto y la validez del derecho. Barcelona, España: Gedisa, $2^{a}$ ed.

Dworkin, R. (1988). El imperio de la justicia. Barcelona, España: Gedisa

Dworkin, R. (2007). La justicia con toga. Madrid, España: Marcial Pons.

Gadamer, H.G. (2000). Verdad y método. Barcelona, España: Sígueme.

Habermas, J. (2002). Verdad y justificación. Madrid, España: Trotta.

Putnam, H. (2004). El desplome de la dicotomía hecho-valor y otros ensayos. Barcelona, España: Paidós.

Putnam, H. (2013). Ética sin ontología. Barcelona, España: Alpha Decay.

Radruch, G. (1980). El hombre en el derecho. Buenos Aires, Argentina: De Palma.

Ruiz Miguel, A. (2020). Cuestiones de principios: entre política y Derecho. Madrid, España: Centro de Estudios Políticos y Constitucionales. 